\title{
A PROSPECTIVE STUDY OF INTRAOPERATIVE COMPARISON BETWEEN GENERAL ANAESTHESIA WITH CONVENTIONAL OPIOID AND THORACIC EPIDURAL ANAESTHESIA FOR OFF PUMP CORONARY ARTERY BYPASS SURGERY
}

\author{
Nameirakpam Charan¹, Mangesh Chaudhary², Manish Sonkusale3, Rashmi Deshpande4 \\ ${ }^{1}$ Assistant Professor, Department of Cardiac Anaesthesiology and Critical Care, Jawaharlal Nehru Institute of Medical Sciences, \\ Imphal-East, Manipur, India. \\ ${ }^{2}$ Assistant Professor, Department of Cardiac Anaesthesia, Jawaharlal Nehru Medical College, AVBRH, Sawangi, Maharashtra, India. \\ ${ }_{3}^{3}$ Associate Professor, Department of Cardiac Anaesthesia, Jawaharlal Nehru Medical College, AVBRH, Sawangi, Maharashtra, India. \\ ${ }^{4}$ Professor, Department of Cardiac Anaesthesia, Jawaharlal Nehru Medical College, AVBRH, Sawangi, Maharashtra, India.
}

\section{BACKGROUND} ABSTRACT

Coronary artery disease (CAD) is one of the most common causes of mortality and morbidity amongst cardiovascular diseases in both developed and developing countries. The prevalence of CAD in India is 14\% in urban and $7.4 \%$ in rural populations. Perioperative advantage of TEA (thoracic epidural anaesthesia) is enhanced coronary perfusion, improved myocardial oxygen balance and reduced incidence of tachyarrhythmia and myocardial ischemia through sympatholysis.

\section{METHODS}

108 patients for OPCAB were selected and divided into two groups (GA and GATE). In GATE group, Epidural insertion was done in the evening, 1 day before surgery. Neuraxial block was achieved from T1 to T10 segments with epidural $10 \mathrm{ml}$ infusion of $0.5 \%$ bupivacaine with $0.5 \mathrm{mcg} / \mathrm{kg}$ fentanyl as bolus dose over a period of 10 minutes followed by infusion of $0.25 \%$ bupivacaine with fentanyl $2 \mathrm{mcg} / \mathrm{ml} @ 5 \mathrm{ml} / \mathrm{hr}$ intraoperatively. In GA Group, maintenance dose of intravenous fentanyl $1 \mathrm{mcg} / \mathrm{kg}+\mathrm{midazolam} 0.03$ $\mathrm{mg} / \mathrm{kg}$ were given intermittently and when there was increase in mean arterial pressure or heart rate above $20 \%$ from the baseline. All patients were induced with Thiopental $2.5 \mathrm{mg} / \mathrm{kg}+$ Fentanyl $3 \mathrm{mcg} / \mathrm{kg}+$ Midazolam $0.03 \mathrm{mg} / \mathrm{kg}+\mathrm{Vecuronium} 0.1$ $\mathrm{mg} / \mathrm{kg}$, ventilated with $100 \% \mathrm{O}_{2}$ for 3 minutes and intubated with cuffed endotracheal tube of appropriate size. Before skin incision, injection fentanyl $1 \mathrm{mcg} / \mathrm{kg}$, vecuronium $0.02 \mathrm{mg} / \mathrm{kg}$ were repeated and surgery was started. Anaesthesia was maintained with air $(50 \%)+$ oxygen $(50 \%)+$ isoflurane $1 \%$ dial conc.+ intermittent bolus dose of vecuronium $0.02 \mathrm{mg} / \mathrm{kg}$. Heparin $(150$ $\mathrm{IU} / \mathrm{kg}$ ) was administered via central venous line after completion of LIMA harvesting to achieve an activated clotting time of 250 350 s. At the end of the surgery patient were shifted to CVTS-ICU and ventilated with SIMV volume control with pressure support mode.

\begin{abstract}
RESULTS
Superior haemodynamic stability could be achieved via thoracic epidural anaesthesia. heart rate at baseline $(p$ value $=0.563)$ and after induction ( $p$ value $=0.438$ ) were similar and comparable in both the groups. There is more haemodynamic variability during circumflex or obtuse marginal anastomosis (GA - 85.78 \pm 7.32 \& GATE -77.06 \pm 8.33 ). The median duration of surgery in GATE group is 5 hours 30 minutes (IQR- 0-1.00) which is significantly higher than GA group with 5 hours (IQR-0-0.63). In GATE group 83.34\% of the patients were extubated earlier within 8 hours as compared to $62.96 \%$ in GA group.
\end{abstract}

\section{CONCLUSIONS}

We have observed that combined thoracic epidural anaesthesia with general anaesthesia reduces stress response to intubation, better perioperative haemodynamic stability and earlier extubation.

HOW TO CITE THIS ARTICLE: Charan N, Chaudhary M, Sonkusale M, et al. A prospective study of intraoperative comparison between general anaesthesia with conventional opioid and thoracic epidural anaesthesia for off pump coronary artery bypass surgery. J. Evolution Med. Dent. Sci. 2019;8(20):1667-1677, DOI: 10.14260/jemds/2019/368

\section{BACKGROUND}

Coronary artery disease (CAD) is one of the most common causes of mortality and morbidity amongst cardiovascular diseases in both developed and developing countries. The prevalence of CAD in India is $14 \%$ in urban and $7.4 \%$ in rural populations. ${ }^{1}$ Most commonly conducted surgeries for

'Financial or Other Competing Interest': None.

Submission 28-03-2019, Peer Review 01-05-2019,

Acceptance 08-05-2019, Published 20-05-2019.

Corresponding Author:

Dr. Nameirakpam Charan,

Department of Anaesthesia,

Jawaharlal Nehru Institute of Medical Sciences (JNIMS),

Porompat-795005, Imphal-East, Manipur, India.

E-mail: charan.nameirakpam@gmail.com

DOI: $10.14260 /$ jemds $/ 2019 / 368$ coronary artery disease are on pump coronary artery bypass and off pump coronary artery bypass surgery. Outcomes after cardiac surgery have been markedly improved over recent decade because of improvements in new techniques, drugs and equipment's in anaesthesiology, surgery, cardiopulmonary bypass (CPB) and post-operative care. Offpump coronary artery bypass (OPCAB) surgery is a technically more demanding strategy of myocardial revascularization compared with the standard on-pump technique. It attenuates complications related to cardiopulmonary bypass, including systemic inflammatory response, coagulopathies, platelet dysfunction, fibrinolysis, consumption of clotting factors, neurological injury, renal impairment and atrial fibrillation.

Earlier, OPCAB surgery was conducted under conventional opioid base general anaesthesia. Later in 1976 
thoracic epidural was first reported by Hoer et $\mathrm{al}^{2}$ in patients undergoing cardiac surgeries. The objective of thoracic block is not solely to block noxious afferent stimuli from the surgical site, but to impart a bilateral selective thoracic sympathectomy. According to study conducted by Chanaka Rajakaruna ${ }^{3}$ et al, coronary artery bypass surgery (CABG) via median sternotomy using opioid anaesthesia leads to sympathetic activation by surgical stress causing tachycardia, hypertension and increased oxygen demand and extraction by the myocardium. Combining epidural anaesthesia with general anaesthesia in OPCAB surgery is expected to have a synergistic effect on reducing sympathetic stress. Massimo Caputo et al. (2011) concluded that addition of thoracic epidural to general anaesthesia significantly reduces the incidence of postoperative arrhythmias and improves pain control and overall quality of recovery, allowing earlier extubation and hospital discharge. ${ }^{4}$ N. Noiseux et al studied 15 case series on awake coronary artery bypass grafting combining with high thoracic epidural and femoral nerve block with a good result. They also mentioned that OPCAB is the main domain for this technique. ${ }^{5}$

Perioperative advantage of TEA (Thoracic epidural anaesthesia) is enhanced coronary perfusion, improve myocardial oxygen balance and reduce the incidence of tachyarrhythmia and myocardial ischemia through sympatholysis. The various additional advantages of thoracic epidural anaesthesia supplementing general anaesthesia are better pain control and early extubation. The important fear of thoracic epidural is epidural Haematoma (Incidence is $1: 10000) .{ }^{6}$ But if a proper protocol is observed, it is a very rare incidence. Nevertheless, intravenous opioids administration is associated with a range of side effects including respiratory depression requiring reintubation, sedation and lethargy, nausea and vomiting, constipation, urinary retention, pruritus and paralytic ileus requiring multimodal pain management techniques

In this study, we compared intraoperative haemodynamic parameters and time of extubation, in both conventional general anaesthesia with intravenous opioids and general anaesthesia with epidural groups.

So, we hypothesised that Thoracic Epidural anaesthesia will be beneficial in intraoperative elective Off Pump Coronary Artery Bypass Grafting Surgery.

\section{Aim of The Study}

The aim of this open randomized controlled trial study was to evaluate the effect of thoracic epidural anaesthesia on early clinical outcomes in patients undergoing off pump coronary artery bypass surgery.

\section{Objectives}

\section{Primary Objectives}

1. To compare the haemodynamic stability in 2 groups of off pump coronary artery bypass surgery.

\section{Secondary Objectives}

1. To compare the stress response to intubation in 2 groups.

2. To compare the extubation time in 2 groups.

\section{METHODS}

This prospective, open, randomized, controlled study was carried out in the Department of Cardiac Anaesthesia, Acharya Vinobha Bhave Rural Hospital (AVBRH), Sawangi (Meghe) Wardha from December 2015 to December 2017. Permission from college ethical committee was taken for conduct of study. 108 patients for OPCAB were selected and divided into two groups (GA and GATE) with 54 patients in each group. These patients were posted for elective off pump Coronary Artery Bypass Graft surgery (OPCABG) in the Department of CVTS, AVBRH.

\section{Inclusion Criteria}

1. Patient posted for elective off pump coronary artery bypass graft (OPCABG) alone - requiring - 1 to 4 grafts

2. $\mathrm{EF}>30 \%$

3. Age- $35-80$ yrs.

4. Euroscore $<5$

5. Patients with antiplatelet and anticoagulant drugs stopped well in time. (Unfractionated Heparin- $4 \mathrm{hrs,}$ Low Molecular Weight Heparin-12 hrs, Aspirin- 5 days, clopidogrel -7 days, Ticlopidine-14 days)

6. Normal coagulation profile-. (APTT $<40 \mathrm{sec}$, INR $<1.5$, platelet count $>1$ lack)

7. Patient of both sexes.

\section{Exclusion Criteria}

1. Patient having systemic diseases - cerebrovascular, liver, Kidney (creatinine $>2$ ) and haematological diseases,

2. Emergency $\mathrm{CABG}$ or combined procedures $(\mathrm{CABG}+$ valvular surgery, $\mathrm{CABG}+$ carotid endarterectomy)

3. Patient on low molecular weight heparin and anticoagulant treatment.

4. Patients not satisfying coagulation criteria (APTT $>40$ sec., INR $>1.5$ platelet count $<1.5$ lack)

5. Contraindications to epidural anaesthesiacoagulopathies, spine disorders, previous spine surgery, allergy to local anaesthetics, and local infection.

6. Patient refusal.

7. If bloody tap due to traumatic epidural.

On the night before surgery, patients were randomized to one of two groups by computer generated random number.

Group GA $=54$ patients (general anaesthesia plus conventional intravenous opioid analgesia).

Group GATE $=54$ patients (general anaesthesia plus perioperative thoracic epidural analgesia)

\section{Preanaesthetic Check-Up}

During pre-anaesthetic visit, thorough clinical general and systemic examination was done. Pulse rate, blood pressure, respiratory rate, and other co-morbid conditions were recorded. Clinical examination including neurological examination for deep tendon reflexes, muscle tone, and power in the limbs was done. Patients were given all the relevant information about the procedure, advantages and complications of epidural analgesia especially regarding epidural hematoma formation and its consequences and written informed consent was obtained from each patient. All demographic data recorded, and investigations as mentioned 
in the Performa were noted at that time. Clopidogrel and aspirin were stopped 7 days and 1 day respectively prior to the surgery as an institutional protocol. Angiotensinconverting enzyme inhibitors were advised to suspend a day before surgery, while calcium-channel antagonists and $\beta$ adrenergic blocking drugs continued until the morning of surgery. Premedication in both groups consisted of alprazolam $0.25 \mathrm{mg}$, syrup Duphalac $15 \mathrm{ml}$ the night before surgery; while pantoprazole $40 \mathrm{mg}$ orally were given $2 \mathrm{~h}$ before surgery.

\section{Technique of Anaesthesia}

\section{Thoracic Epidural Catheter Insertion}

As per the randomisation, patients were selected for thoracic epidural insertion. Epidural insertion was done in the evening 1 day before surgery in GATE group. An intravenous line secured, basic monitors attached, and 5 litres of oxygen given by mask.

Position- Sitting position

Space selected- $\mathrm{T}_{2}-\mathrm{T}_{3}$ or $\mathrm{T}_{3}-\mathrm{T}_{4}$

Size of Needle - 18 Gauge (BD Touhy epidural needle)

Epidural catheter - 20 Gauge

Under all aseptic precaution, 2\% lignocaine is infiltrated locally. Through paramedian or midline route, epidural space was approached by loss of resistance technique. The epidural catheter is threated up to $3-5 \mathrm{~cm}$ cephalad. The location of the catheter was then verified with non-pharmacological three step test by Murray et al6. In case of "bloody tap", it was decided to exclude from the study and if the neurological examination was completely normal patient was taken for surgery next day.

\section{Analgesia Technique for Groups \\ GA Group \\ Intra-Operative Protocol}

Maintenance dose of intravenous fentanyl $1 \mathrm{mcg} / \mathrm{kg}+$ midazolam $0.03 \mathrm{mg} / \mathrm{kg}$ were given intermittently and when there was increase in mean arterial pressure or heart rate above $20 \%$ from the baseline.

\section{GATE Group}

\section{Intra-Operative Protocol}

20 minutes before induction of general anaesthesia neuraxial block up to T1 to T10 segments was established with epidural $10 \mathrm{ml}$ infusion of $0.5 \%$ bupivacaine with $0.5 \mathrm{mcg} / \mathrm{kg}$ fentanyl as bolus dose over a period of 10 minutes followed by infusion of $0.25 \%$ bupivacaine with fentanyl $2 \mathrm{mcg} / \mathrm{ml} @ 5$ $\mathrm{ml} / \mathrm{hr}$. Intra-operatively. Determination of the height of block was performed by cold sensation to ice before induction of GA. Failure to obtain a block with $10 \mathrm{ml}$ of $0.5 \%$ bupivacaine was considered misplacement of the epidural technique; alternative method of analgesia was implemented in those cases, and the patient was excluded from analysis

With all aseptic precautions, epidural catheter was removed 48 hours after the surgery after a bolus dose of $10 \mathrm{ml} 0.125 \%$ bupivacaine with $20 \mathrm{mcg}$ of fentanyl.

\section{General Anaesthesia Technique in Both Groups}

On the day of surgery ASA standard monitors were attached and an intravenous line secured. Patients were premeditated with midazolam $0.03 \mathrm{mg} / \mathrm{kg}$ and all invasive lines (radial artery, femoral artery and central venous) were cannulated under local anaesthesia with all aseptic precautions. All patients were induced with Thiopental $2.5 \mathrm{mg} / \mathrm{kg}+$ Fentanyl $3 \mathrm{mcg} / \mathrm{kg}+$ Midazolam $0.03 \mathrm{mg} / \mathrm{kg}+$ Vecuronium $0.1 \mathrm{mg} / \mathrm{kg}$, ventilated with $100 \% \mathrm{O}_{2}$ for 3 minutes and intubated with cuffed endotracheal tube of appropriate size. Intraoperative monitoring included continuous arterial blood pressure, heart rate, 5 lead electrocardiography with ST segment analysis, (Central venous pressure) CVP, nasopharyngeal temperature, urine output, peripheral capillary oxygen saturation $\left(\mathrm{SpO}_{2}\right)$, end tidal carbon dioxide $\left(\mathrm{EtCO}_{2}\right)$ along with baseline arterial blood gas (ABG) analysis. Transoesophageal echocardiography probe was inserted 5 minutes after intubation. Before skin incision, injection fentanyl $1 \mathrm{mcg} / \mathrm{kg}$, vecuronium $0.02 \mathrm{mg} / \mathrm{kg}$ were repeated and surgery was started. Anaesthesia was maintained with air $(50 \%)+$ oxygen $(50 \%)+$ Isoflurane $1 \%$ dial conc.+ intermittent bolus dose of vecuronium $0.02 \mathrm{mg} / \mathrm{kg}$. End-tidal carbon dioxide was maintained between 35 and $40 \mathrm{mmHg}$ throughout by adjusting ventilation. Temperature was maintained at 34-36 degrees Celsius. Intra operative haemodynamics were recorded as per the protocols.

All the operations were performed by one surgeon. All the drugs (midazolam $0.03 \mathrm{mg} / \mathrm{kg}$, fentanyl $1 \mathrm{mcg}$ and vecuronium $0.02 \mathrm{mg} / \mathrm{kg}$ ) were repeated as bolus, before sternotomy if required and every 2 hours' interval. Heparin (150 IU/kg) was administered via central venous line after completion of LIMA harvesting to achieve an activated clotting time of 250-350s. Heparin was repeated to maintain ACT between 250-350s. All anastomoses were performed with standard positioning of heart and a suction stabilizer device (Medtronic tissue stabilizer 29403 octopus 4.3) was used for the distal anastomosis.

Intraoperative haemodynamic management was similar for both groups and aimed to maintain the MAP between 65 and $100 \mathrm{mmHg}$. Hypotension was treated with positioning, intravenous crystalloid fluids until CVP 8-10 mm $\mathrm{Hg}$. Noradrenalin $0.05 \mu \mathrm{g} / \mathrm{kg} / \mathrm{min}$ was started when the SBP was $<90 \mathrm{mmHg}$ persistently and was increased to $0.1 \mu \mathrm{g} / \mathrm{kg} / \mathrm{min}$ if required. Noradrenalin was supplemented by adrenaline $0.05 \mu \mathrm{g} / \mathrm{kg} / \mathrm{min}$ in case of persistent hypotension and increased to $0.1 \mu \mathrm{g} / \mathrm{kg} / \mathrm{min}$ if necessary. Hypertension was treated with IV fentanyl $2 \mu \mathrm{g} / \mathrm{kg}$ bolus in the GA group or with a bolus of epidural 0.25 bupivacaine $2 \mathrm{ml}$ in the GATE group. Persistent hypertension was treated with nitroglycerin infusion $(0.05 \mu \mathrm{g} / \mathrm{kg} / \mathrm{min}-0.01 \mu \mathrm{g} / \mathrm{kg} / \mathrm{min})$ in both groups.

In case of malignant arrhythmia, haemodynamic instability, persistent elevation or depression of ST- T segment $>2.5 \mathrm{~mm}$ from baseline, OPCABG was converted to on pump CABG and the case was excluded from the study ${ }^{7}$

On completion of all distal and proximal anastomoses, once surgical bleeding was controlled and the patient was haemodynamically stable with acceptable blood gas analysis report, protamine sulphate $(1 \mathrm{mg} / 100 \mathrm{IU}$ of heparin) was given slowly via the central venous line to reverse the effect of heparin to achieve the ACT below 150 seconds. Injectable $\beta$-blockers were not used intra-operatively or postoperatively during the study period in any patient, unless indicated.

At the end of the surgery patient were shifted to CVTSICU and ventilated with SIMV volume control with pressure support mode.

Patients were extubated after fulfilling the following criteria- 
1. Patient responsive to verbal command.

2. Oxygen saturation $>94 \%$ on inspired oxygen concentration $<50 \%$.

3. Respiratory rate $<20$ breaths/min and no obvious respiratory distress.

4. $\mathrm{PaCO}_{2}<50 \mathrm{~mm} \mathrm{Hg}, \mathrm{pH}>7.30$.
5. Tidal volume $>7 \mathrm{~mL} / \mathrm{kg}$ with pressure support $<10 \mathrm{~cm}$ $\mathrm{H}_{2} \mathrm{O}$ above the end-expiratory pressure.

6. Temperature $>36.0^{\circ} \mathrm{C}$

7. Chest tube drainage $<100 \mathrm{~mL} / \mathrm{h}$.

8. Haemodynamic stability (i.e., not requiring significant inotropic support and no uncontrolled arrhythmia)

\section{RESULTS}
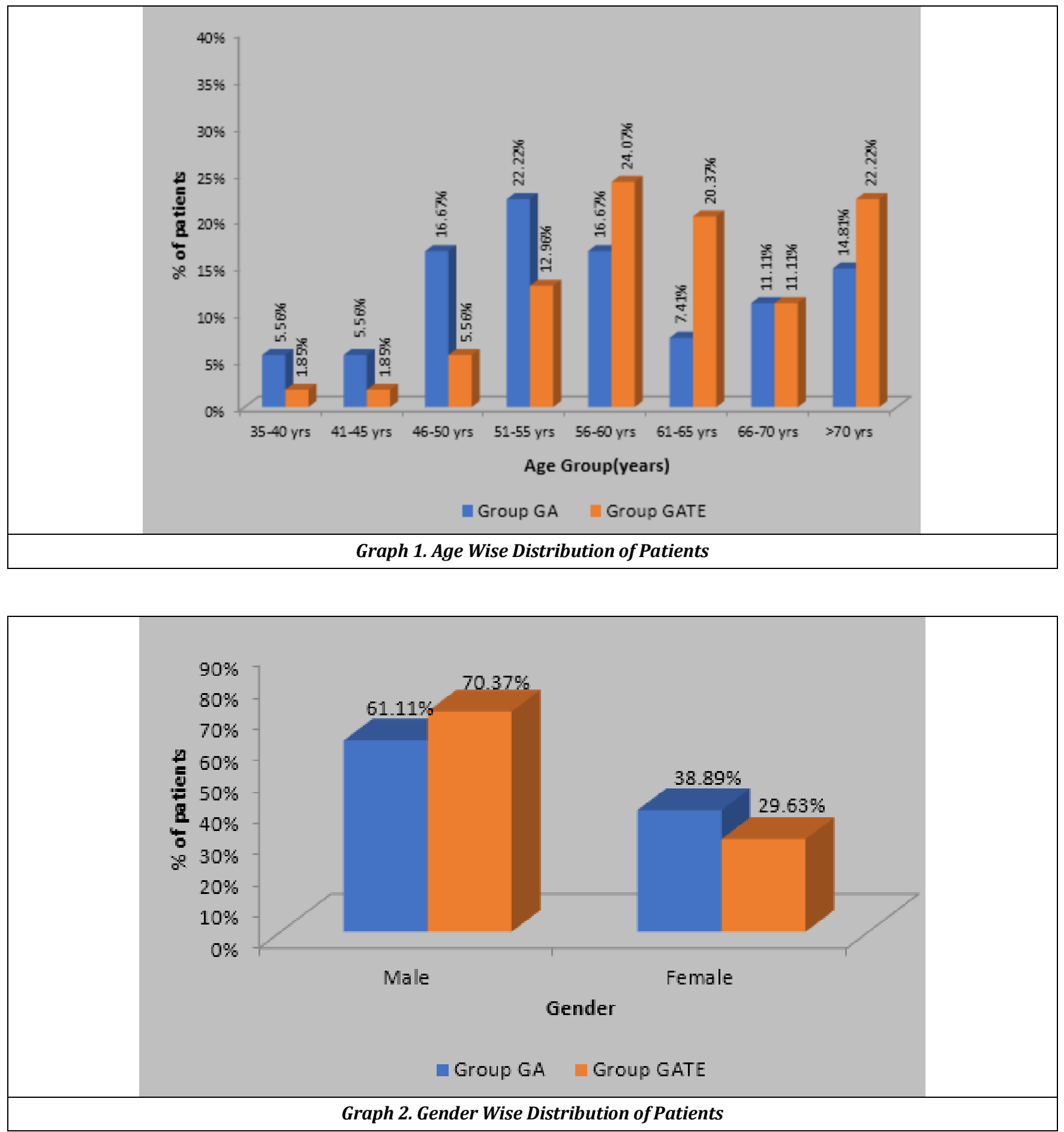

\begin{tabular}{|c|c|c|c|c|c|c|c|}
\hline Variables & Group & $\mathbf{N}$ & Mean & Std. Deviation & Std. Error Mean & t-Value & p-Value \\
\hline \multirow{2}{*}{ EuroSCORE II } & GA & 54 & 1.99 & 0.86 & 0.11 & \multirow{2}{*}{0.91} & \multirow{2}{*}{$0.36, \mathrm{NS}$} \\
\hline & GATE & 54 & 2.13 & 0.75 & 0.10 & & \\
\hline \multirow{2}{*}{$\begin{array}{c}\text { Pre-Operative Left } \\
\text { Ventricular Ejection } \\
\text { Fraction }\end{array}$} & GA & 54 & 54.07 & 5.93 & 0.80 & \multirow{2}{*}{1.14} & \multirow[b]{2}{*}{$0.254, \mathrm{NS}$} \\
\hline & GATE & 54 & 52.74 & 6.14 & 0.83 & & \\
\hline
\end{tabular}



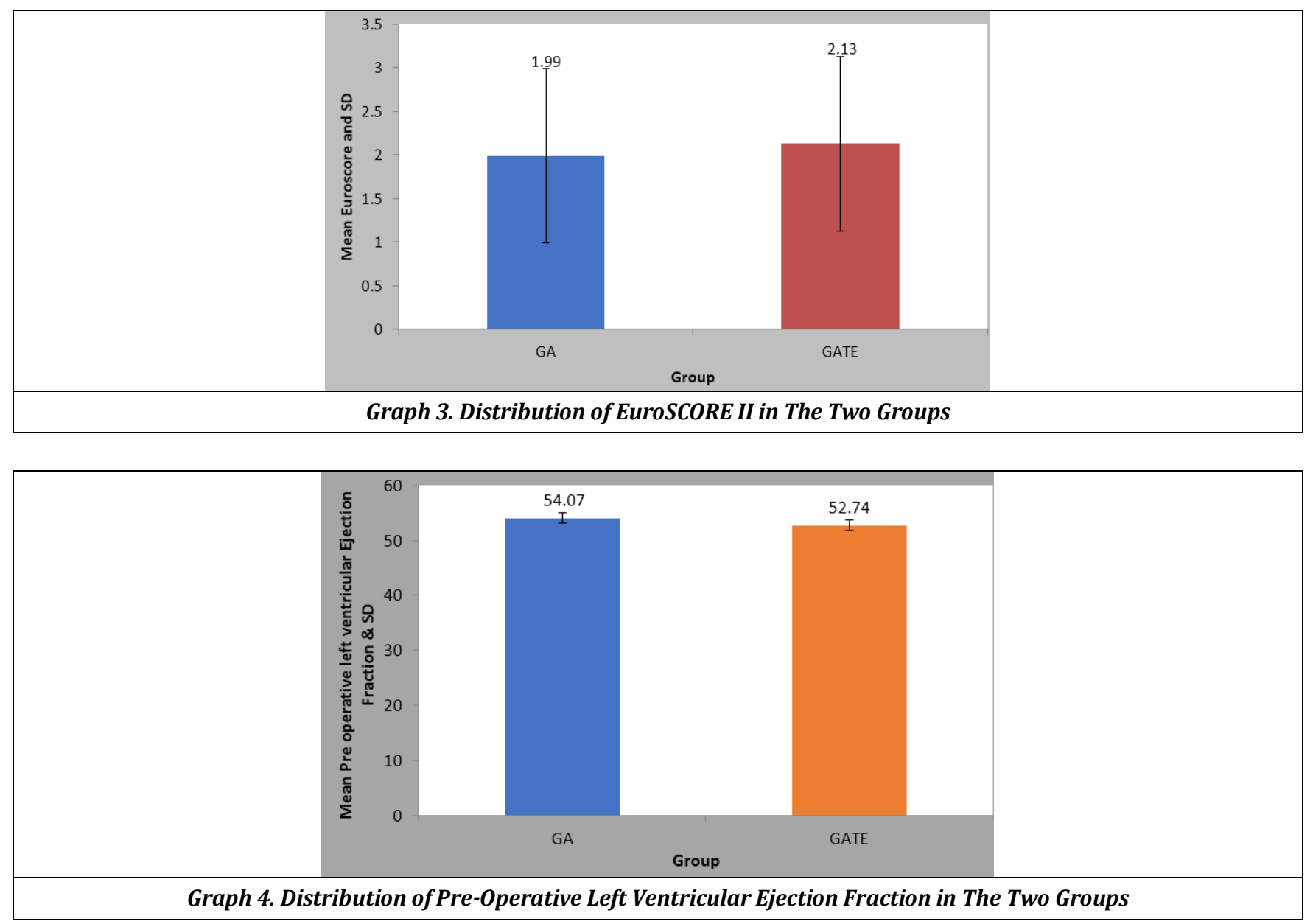

Table 1 and graphs 3\&4 are showing distribution of EuroSCORE II and left ventricular ejection fraction. Mean EuroSCORE II are $1.99 \pm 0.86$ and $2.13 \pm 0.75$ for GA group and GATE group respectively. EuroSCORE II in both groups are in moderate risk limit and the difference is not significant with p-value of 0.36 . The pre-operative left ventricular ejection fraction is also comparable with pvalue of 0.254 .

\begin{tabular}{|c|c|c|c|c|}
\hline Variable & Group GA (n=54) & Group Gate (n=54) & $\chi 2$-Value & p-Value \\
\hline H/O HTN & $22(40.74 \%)$ & $20(37.04 \%)$ & 0.15 & 0.69, NS \\
\hline H/O DM & $21(38.89 \%)$ & $32(59.26 \%)$ & 4.48 & $0.034, \mathrm{~S}$ \\
\hline H/O Smoking & $25(46.30 \%)$ & $28(51.85 \%)$ & 0.33 & $0.56, \mathrm{NS}$ \\
\hline Preoperative $\beta$-Blocker & $25(46.30 \%)$ & $22(40.74 \%)$ & 0.33 & $0.56, \mathrm{NS}$ \\
\hline \multicolumn{4}{|l}{ Table 2. Showing Co-Morbidities in The Two Groups } \\
\hline
\end{tabular}

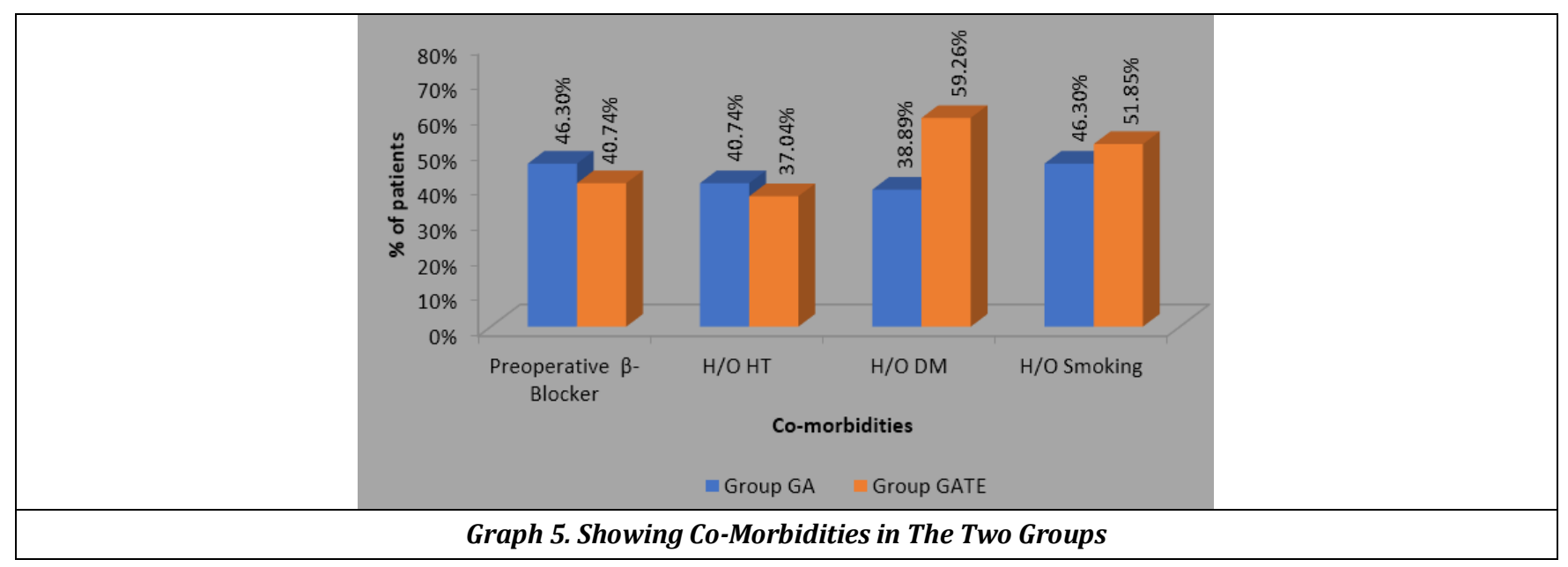


Table 2 and graph 5 are showing comorbidities in both groups. Pre-operative $\beta$-blocker (p-value=0.56) and co-morbid conditions like smoking ( $p$-value=0.56) and hypertension ( $p$-value=0.69) were comparable in both groups but there were significantly more diabetic patients in the GATE groups which was statistically significant.

\begin{tabular}{|c|c|c|c|c|c|c|}
\hline \multirow[t]{2}{*}{ Time Interval } & \multicolumn{2}{|c|}{ Group GA } & \multicolumn{2}{|c|}{ Group GATE } & \multirow{2}{*}{ t-Value } & \multirow{2}{*}{ p-Value } \\
\hline & Mean & SD & Mean & SD & & \\
\hline $\mathrm{BL}$ & 75.83 & 9.49 & 74.80 & 9.07 & 0.58 & $0.563, \mathrm{NS}$ \\
\hline AI & 71.13 & 9.00 & 69.87 & 7.77 & 0.77 & $0.438, \mathrm{NS}$ \\
\hline AIT & 87.26 & 7.45 & 73.33 & 6.65 & 10.24 & $0.0001, \mathrm{~S}$ \\
\hline 5M AIT & 92.41 & 7.06 & 70.06 & 8.15 & 15.23 & $0.0001, \mathrm{~S}$ \\
\hline SI & 96.61 & 8.05 & 72.89 & 8.81 & 14.60 & $0.0001, \mathrm{~S}$ \\
\hline ST & 80.15 & 8.20 & 71.57 & 8.54 & 5.32 & $0.0001, \mathrm{~S}$ \\
\hline LH & 75.65 & 7.08 & 73.33 & 9.46 & 1.44 & $0.153, \mathrm{NS}$ \\
\hline Graft 1 & 79.50 & 7.03 & 72.00 & 9.16 & 4.77 & $0.0001, \mathrm{~S}$ \\
\hline Graft 2 & 85.78 & 7.32 & 77.06 & 8.33 & 5.78 & $0.0001, \mathrm{~S}$ \\
\hline Graft 3 & 82.63 & 6.45 & 75.22 & 11.15 & 4.22 & $0.0001, \mathrm{~S}$ \\
\hline Graft 4 & 77.50 & 6.78 & 74.17 & 10.63 & 1.94 & $0.055, \mathrm{NS}$ \\
\hline $\mathrm{SC}$ & 83.59 & 10.75 & 76.13 & 11.60 & 3.46 & $0.001, \mathrm{~S}$ \\
\hline BS & 88.17 & 8.67 & 74.89 & 10.85 & 7.02 & $0.0001, \mathrm{~S}$ \\
\hline
\end{tabular}

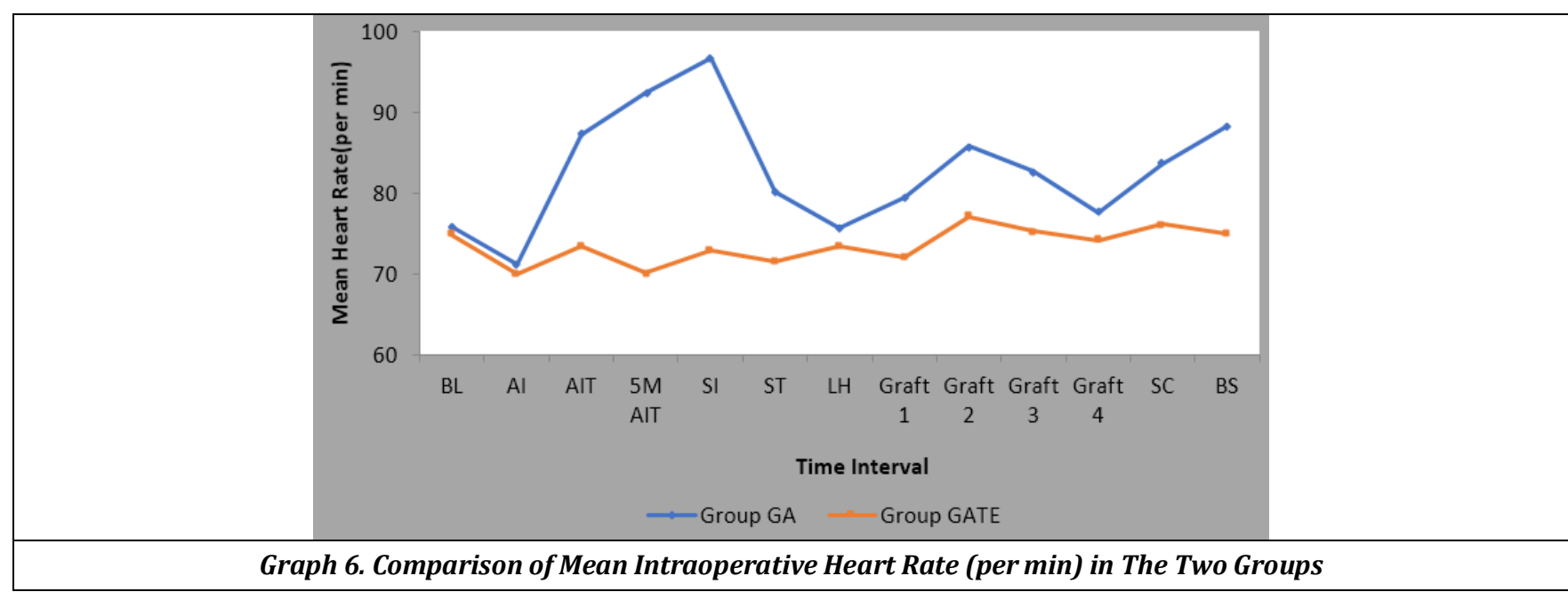

(BL-baseline, AI-after induction, AIT- after intubation, 5M AIT- 5 minutes after intubation, SI- skin incision, ST- sternotomy, LHlima harvesting, Graft 1- Lima to left anterior descending anastomosis, Graft 2- obtuse marginal anastomosis, Graft 3- diagonal anastomosis, Graft 4- posterior descending artery/right coronary artery anastomosis, SC- sternal closer, BS- before shifting)

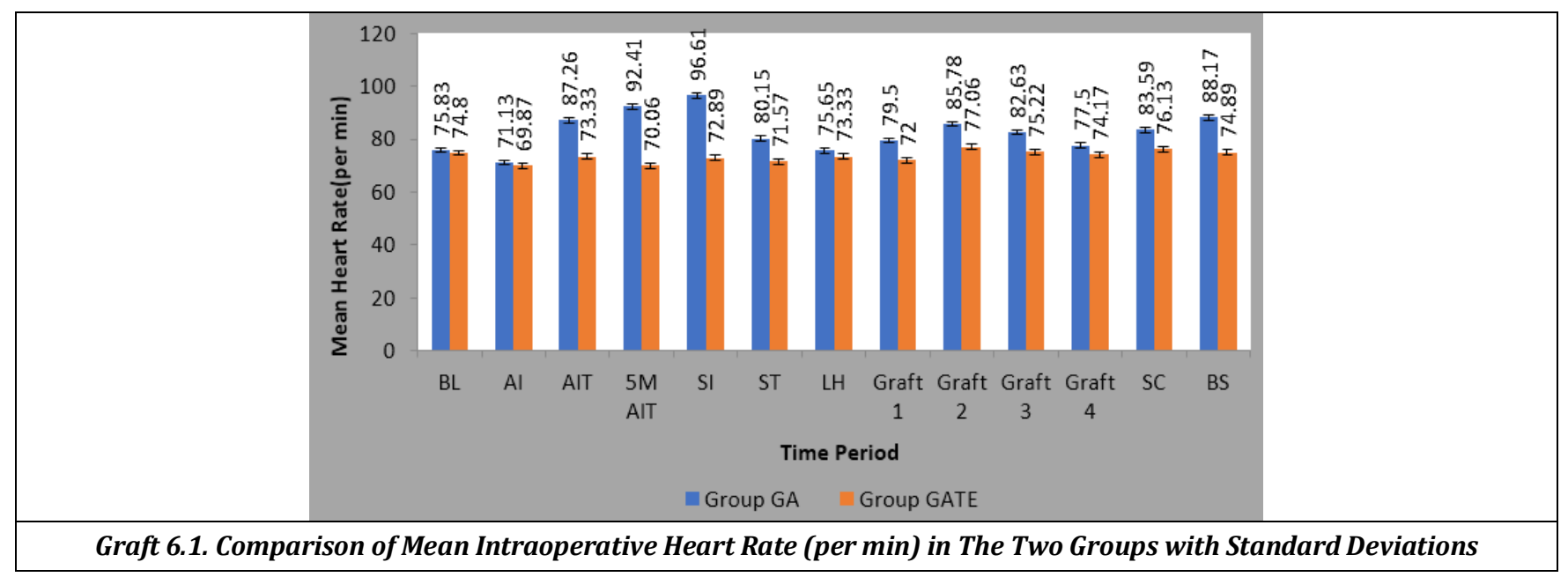

Table 3 and graph 6\&6.1 are showing mean variation of intraoperative heart rate in two groups. Heart rate at baseline (pvalue $=0.563$ ) and after intubation ( $p$-value $=0.438$ ) were similar and comparable in both the groups. There is significantly increase in heart rate after intubation, skin incision, sternotomy, first three grafts, sternal closure and at the end of surgery in GA group compared with a stable and nearing baseline in GATE group 


\begin{tabular}{|c|c|c|c|c|c|c|}
\hline Time Interval & \multicolumn{2}{|c|}{ Group GA } & \multicolumn{2}{c|}{ Group Gate } & \multirow{2}{*}{ t-Value } & \multirow{2}{*}{ p-Value } \\
\hline & Mean & SD & Mean & SD & & $0.102, \mathrm{NS}$ \\
\hline BL & 106.02 & 10.90 & 103.06 & 7.46 & 1.648 & $0.026, \mathrm{~S}$ \\
\hline AI & 94.98 & 7.25 & 91.90 & 6.88 & 2.264 & $0.0001, \mathrm{~S}$ \\
\hline AIT & 108.30 & 7.65 & 99.61 & 5.01 & 6.981 & $0.0001, \mathrm{~S}$ \\
\hline SM AIT & 112.33 & 7.74 & 95.41 & 8.23 & 11.006 & $0.0001, \mathrm{~S}$ \\
\hline SI & 102.81 & 5.02 & 92.12 & 7.33 & 8.842 & $0.0001, \mathrm{~S}$ \\
\hline ST & 98.57 & 5.87 & 90.70 & 6.79 & 6.444 & $0.403, \mathrm{NS}$ \\
\hline LH & 92.17 & 6.34 & 90.91 & 9.08 & 0.840 & $0.004, \mathrm{~S}$ \\
\hline Graft 1 & 88.68 & 7.87 & 84.27 & 7.46 & 2.986 & $0.0001, \mathrm{~S}$ \\
\hline Graft 2 & 75.68 & 5.17 & 69.59 & 6.33 & 5.481 & $0.597, \mathrm{NS}$ \\
\hline Graft 3 & 80.68 & 5.89 & 81.29 & 6.09 & 0.530 & $0.25, \mathrm{NS}$ \\
\hline Graft 4 & 85.38 & 6.80 & 86.90 & 7.16 & 1.13 & $0.0001, \mathrm{~S}$ \\
\hline SC & 93.90 & 8.04 & 88.55 & 7.26 & 3.632 & $0.002, \mathrm{~S}$ \\
\hline BS & 97.65 & 9.40 & 92.61 & 7.04 & 3.151 & \\
\hline
\end{tabular}
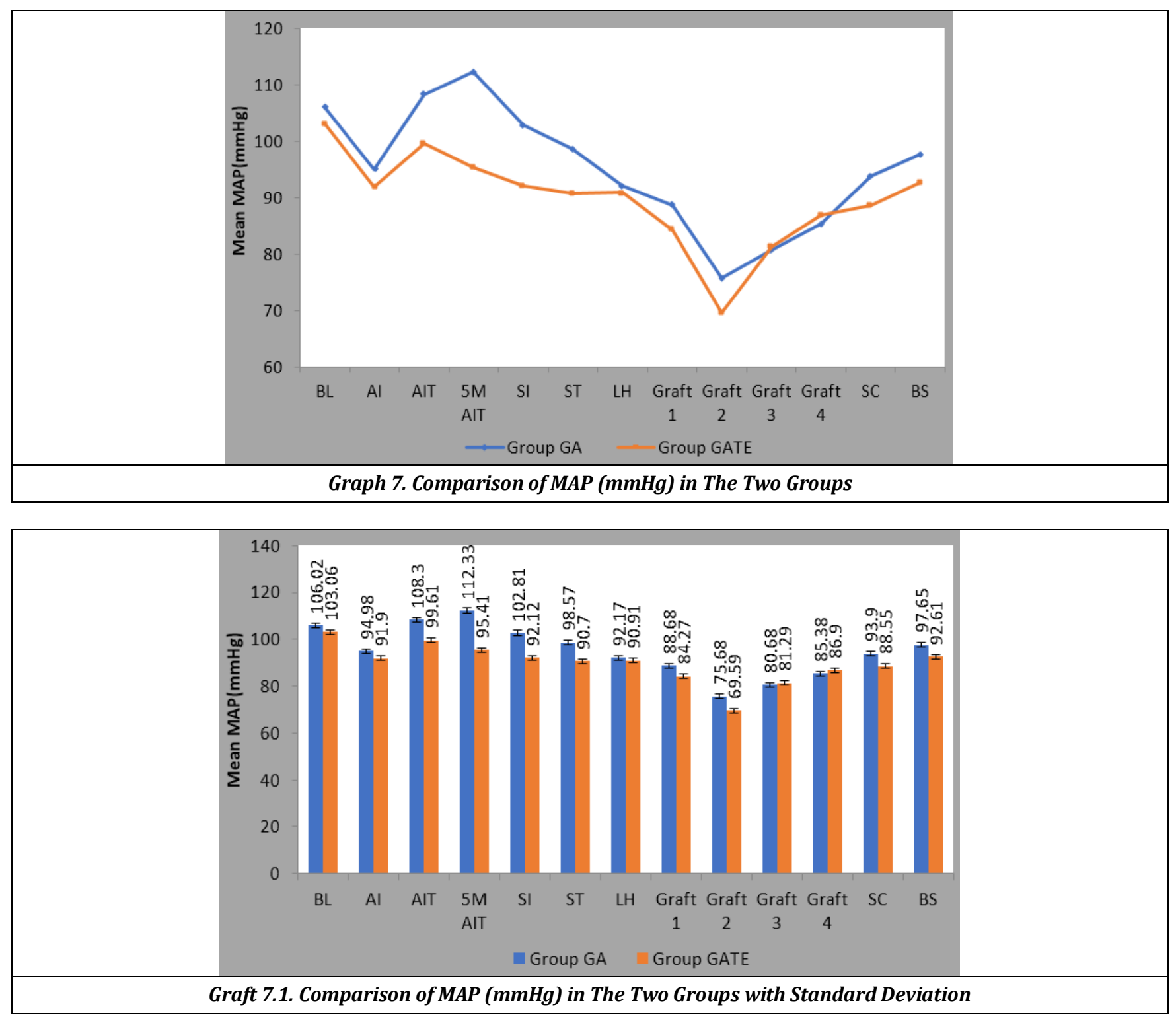

Table 4 and graphs 7\&7.1 are showing mean variation of intraoperative mean arterial pressure (mmHg) in two groups. Baseline of intraoperative mean arterial pressure ( $p$-value $=0.102$ ) is comparable in both groups but there is significant increase in GA group during after intubation, skin incision, sternotomy, first 2 grafts, sternal closure and at the end of surgery in GA but more stable in GATE group. There is significant decrease in mean arterial pressure during anastomosis of the circumflex artery in both groups but more pronounce in GATE group but within physiological limit. Mean arterial pressure during sternal closure and end of surgery are also more stable in GATE group than GA group. 


\begin{tabular}{|c|c|c|c|c|c|c|}
\hline \multirow[t]{2}{*}{ Time Interval } & \multicolumn{2}{|c|}{ Group GA } & \multicolumn{2}{|c|}{ Group GATE } & \multirow{2}{*}{ t-Value } & \multirow{2}{*}{ p-Value } \\
\hline & Mean & SD & Mean & SD & & \\
\hline BL & 6.94 & 3.22 & 7.35 & 3.06 & 0.674 & $0.502, \mathrm{NS}$ \\
\hline $\mathrm{AI}$ & 5.28 & 2.86 & 5.50 & 2.83 & 0.406 & $0.686, \mathrm{NS}$ \\
\hline AIT & 6.93 & 3.14 & 7.06 & 3.22 & 0.212 & $0.833, \mathrm{NS}$ \\
\hline 5M AIT & 7.83 & 2.79 & 7.87 & 2.84 & 0.068 & $0.946, \mathrm{NS}$ \\
\hline SI & 5.59 & 2.53 & 5.74 & 2.49 & 0.307 & $0.760, \mathrm{NS}$ \\
\hline ST & 4.44 & 2.31 & 4.59 & 2.24 & 0.338 & $0.736, \mathrm{NS}$ \\
\hline LH & 4.35 & 2.21 & 4.43 & 2.09 & 0.179 & $0.858, \mathrm{NS}$ \\
\hline Graft 1 & 5.63 & 1.95 & 5.70 & 2.00 & 0.195 & $0.846, \mathrm{NS}$ \\
\hline Graft 2 & 8.19 & 2.27 & 8.26 & 2.24 & 0.171 & $0.865, \mathrm{NS}$ \\
\hline Graft 3 & 8.11 & 2.08 & 8.19 & 2.10 & 0.184 & $0.854, \mathrm{NS}$ \\
\hline Graft 4 & 6.89 & 1.80 & 6.85 & 1.78 & 0.107 & $0.915, \mathrm{NS}$ \\
\hline $\mathrm{SC}$ & 5.89 & 1.74 & 5.63 & 1.73 & 0.775 & $0.440, \mathrm{NS}$ \\
\hline BS & 5.63 & 2.00 & 5.63 & 2.03 & 0.000 & $1.000, \mathrm{NS}$ \\
\hline \multicolumn{7}{|c|}{ Table 5. Showing Mean Variation of Intraoperative CVP $\left(\mathrm{mmH}_{2} \mathrm{O}\right)$ in The Two Groups } \\
\hline
\end{tabular}
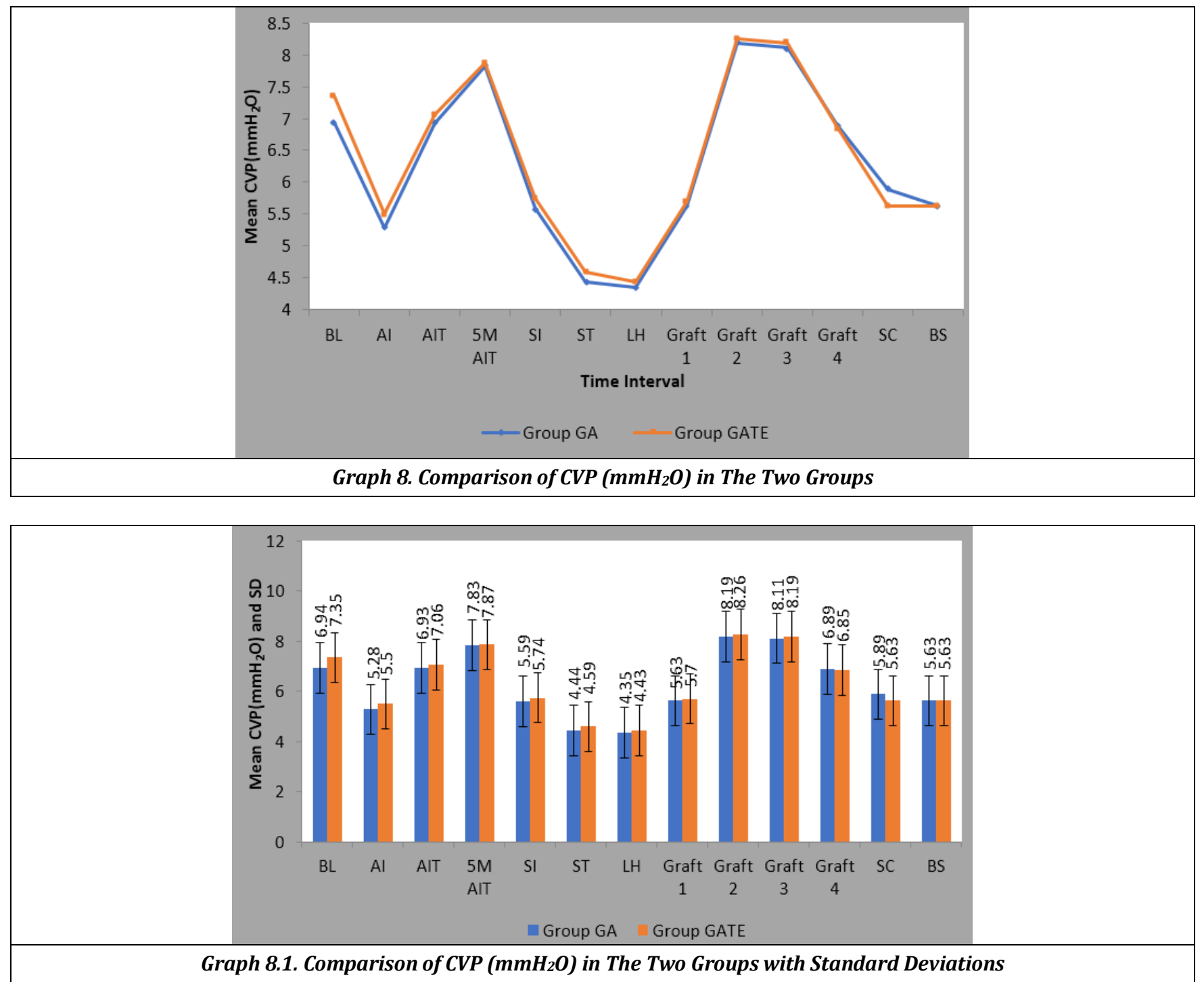

Table 5 and graph 8 \& 8.1 are showing mean variation of Intraoperative Central venous pressure (CVP) in centimetre of water in two groups. There is no significant difference in CVP in both GA and GATE groups.

\begin{tabular}{|c|c|c|c|c|c|}
\hline Group & N & Median & IQR & z-Value & p-Value \\
\hline Group GA & 54 & 5.0 & $0-0.63$ & \multirow{2}{*}{2.31} & \multirow{2}{*}{$0.020, \mathrm{~S}$} \\
\hline Group GATE & 54 & 5.5 & $0-1.00$ & & \\
\hline
\end{tabular}




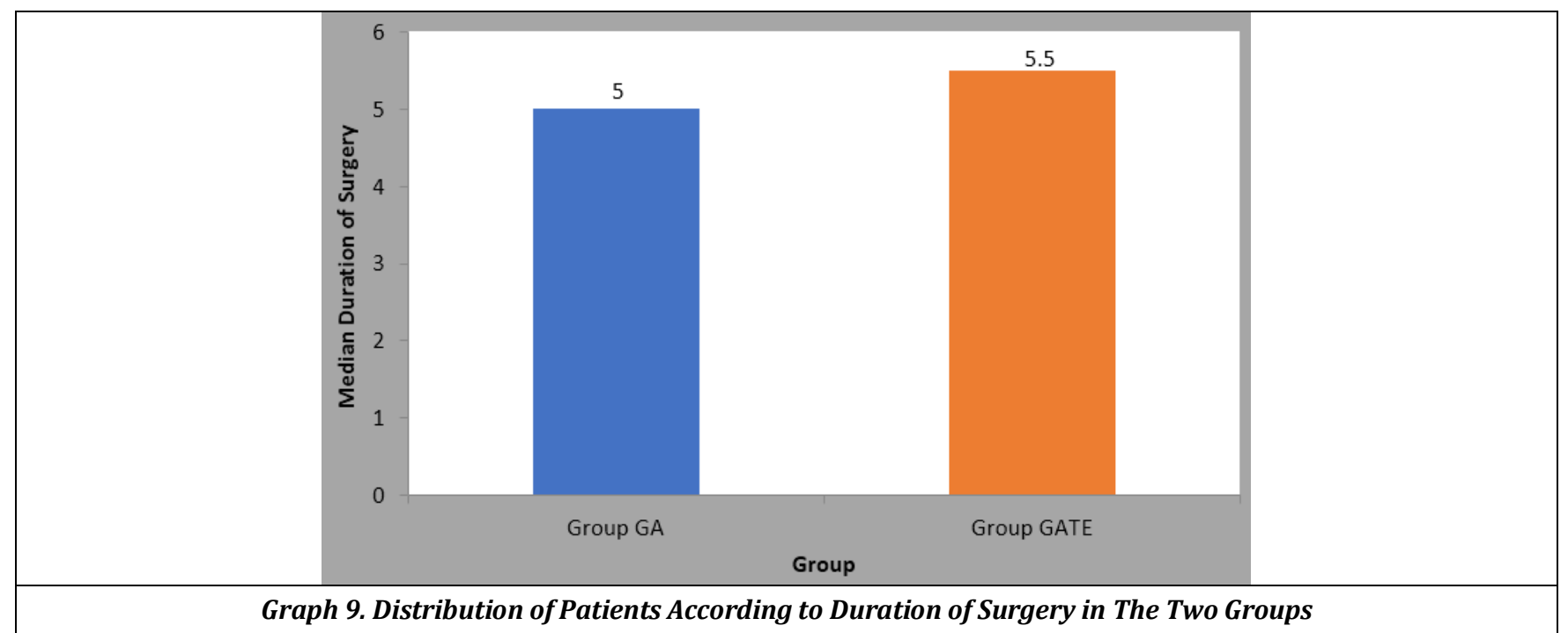

Table 6 and graph 9 are showing distribution of patients according to duration of surgery in hours. The median duration of surgery in GATE group is 5 hours 30 minutes (IQR- 0-1.00) which is significantly higher than GA group with 5 hours (IQR-0-0.63).

\begin{tabular}{|c|c|c|c|c|}
\hline Extubation Time (hrs) & Group GA & Group Gate & $\chi 2$-Value & p-Value \\
\hline 0 to 2 & $5(9.26 \%)$ & $9(16.67 \%)$ & 2.82 & $0.09, \mathrm{~N}$ \\
\hline 3 to 4 & $8(14.81 \%)$ & $16(29.63 \%)$ & 6.45 & $0.011, \mathrm{~S}$ \\
\hline 5 to 8 & $21(38.89 \%)$ & $20(37.04 \%)$ & 0.08 & $0.77, \mathrm{~S}$ \\
\hline 9 to 12 & $13(24.07 \%)$ & $8(14.81 \%)$ & 2.58 & $0.10, \mathrm{~N}$ \\
\hline 13 to 24 & $5(9.26 \%)$ & $1(1.85 \%)$ & 4.71 & $0.029, \mathrm{~S}$ \\
\hline$>24$ & $2(3.70 \%)$ & $0(0 \%)$ & 4.08 & $0.043, \mathrm{~S}$ \\
\hline Total & $54(100 \%)$ & $54(100 \%)$ & & \\
\hline Mean \pm SD & $8.05 \pm 5.26$ & $5.87 \pm 3.52$ & & \\
\hline Median & 7 & 5 & & \\
\hline IQR & $0-7$ & $0-5$ & & \\
\hline \multicolumn{7}{|c|}{} \\
\hline
\end{tabular}

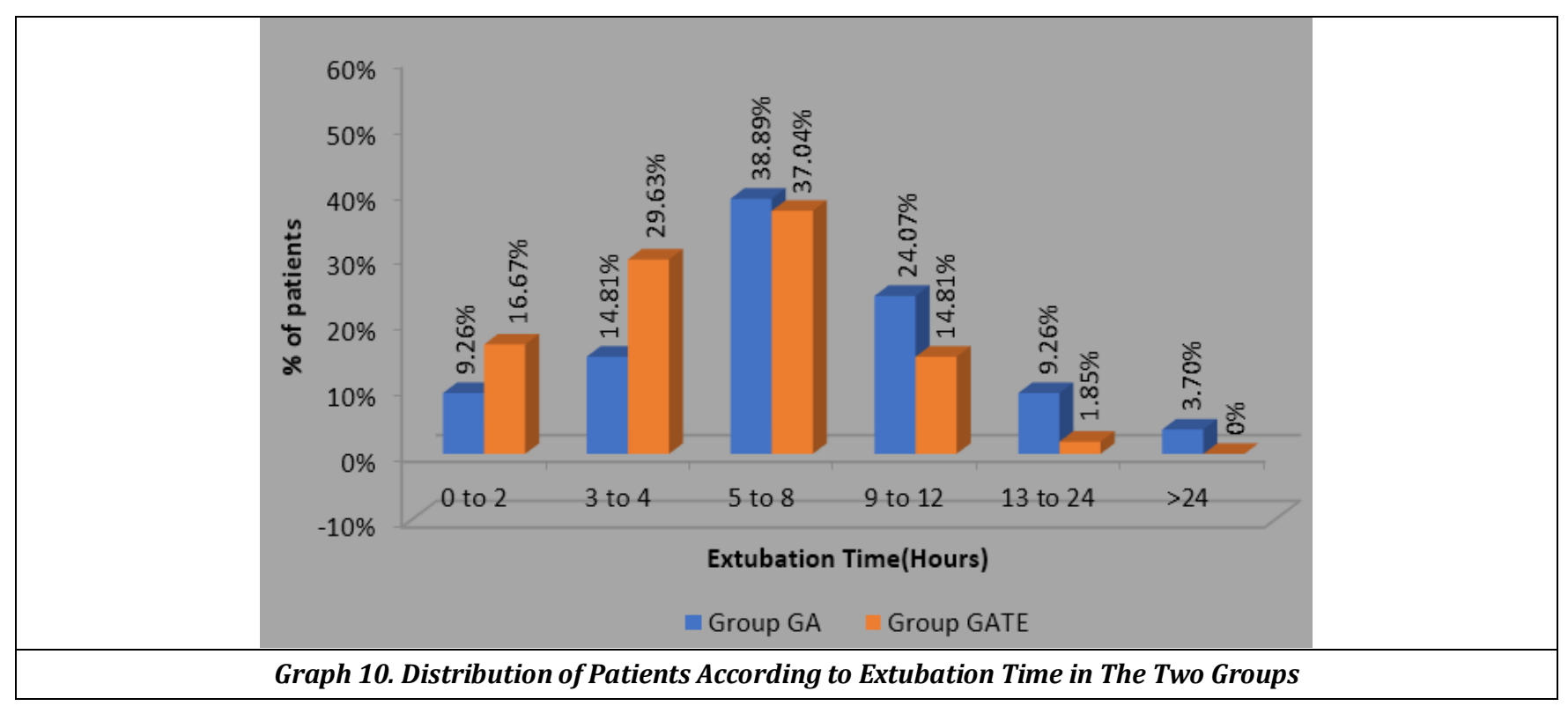

The extubation time were noted in both the groups. Postoperative complications were noted and treated accordingly.

\section{Statistics}

Statistical analysis was done by using descriptive and inferential statistics using chi-square test, student's unpaired $t$ test and software used in the analysis were SPSS Version
22.0 and GraphPad Prism 6.0 version and $\mathrm{p}<0.05$ is considered as level of significance.

Table 7 and graph 10 showing distribution of patients according to extubation time in two groups. Patients were extubated earlier in the GATE group (Median $=5$ hours $\pm 0-7$ ) compare with GA group (Median=7 hours $\pm 0-5$ ) with a significant value at 3-4 hours. In GATE group $83.34 \%$ of the patient extubated earlier within 8 hours as compare to $62.96 \%$ in GA group. 


\section{DISCUSSION}

\section{Demographic Data}

The variables in demographic data were comparable in both the groups but there is significantly more number of diabetic patients in the GATE group (Graph 5) implying more number of high risk cases to be considered in the study, inadvertently. It can be because incidence of coronary artery is more common in diabetic patient. ${ }^{8}$ Associated comorbidities were HTN and respiratory comorbidities associated with smokers. Stefano et al in 2006 reported more incidence of hypotension in female gender. ${ }^{9}$

EuroSCORE is a European system for cardiac operative risk evaluation. EuroSCORE II was used as an indicator to stratify risk in our study (Table 1). It is categorised into mild $(0-2)$, moderate (2-5) and severe ( $>5)$. We have considered EuroSCORE II up to 5 in the present study. 10

\section{Intraoperative Haemodynamic Parameters}

The intraoperative goal is to maintain a stable haemodynamic during off pump coronary artery bypass (OPCABG) surgery. Superior haemodynamic stability could be achieved via thoracic epidural anaesthesia. ${ }^{3}$

In our study, (Table 3 ) heart rate at baseline (pvalue $=0.563$ ) and after induction ( $p$-value $=0.438$ ) were similar and comparable in both the groups. There was statistically significant increase in heart rate after intubation, skin incision, sternotomy, first 3 grafts, sternal closure and at the end of surgery in GA group compared with a stable and nearing baseline in GATE group. The more stable heart rate in the GATE group is due to sympatholytic effect of thoracic epidural to cardiac afferent and efferent adrenergic sympathetic nerve fibres $\left(\mathrm{T}_{1}-\mathrm{T}_{5}\right)$ resulting in loss of chronotropic and inotropic drive to myocardium. ${ }^{4}$ Reduction in heart rate prolong the diastolic filling time and improve coronary perfusion.

Intraoperative baseline mean arterial pressure ( $p$-value $=0.102$ ) was comparable in both groups but there was significant increase in MAP after intubation, at skin incision, sternotomy, first 2 grafts, sternal closure and before shifting the patient from operation theatre in GA group (Table 4). There is significant decrease in mean arterial pressure during anastomosis of the circumflex artery in both groups but more pronounced in GATE group. Mean arterial pressure during sternal closure and end of surgery are also more stable in GATE group than GA group which is statistically significant. Lower mean arterial pressure in the GATE group can be because of vasodilatory effect of thoracic epidural due to sympathetic blockade from $\mathrm{T}_{1}-\mathrm{T}_{10}$. There is more haemodynamic variability during circumflex or obtuse marginal anastomosis (GA - 85.78 \pm 7.32 \& GATE -77.06 \pm 8.33). This haemodynamic instability is due to anatomical alteration during heart positioning. There is also vasodilatory effect on the large epicardial arteries and coronary arterioles improving coronary blood flow and increase myocardial oxygen supply/demand ratio. ${ }^{3}$ There is no significant difference in CVP in both GA and GATE groups (table 5). This may be because of initial filling of the right heart, Trendelenburg positioning and ultimately with inotropic support to maintain haemodynamic intraoperatively.

Intraoperative haemodynamics in our study is also in accordance with previous reports by Massimo caputo et $\mathrm{al}^{4}$ and Chanaka Rajakaruna et al. ${ }^{3}$
Sternotomy and sternal closure are most painful part of the cardiac surgery. In our study, we have observed that there is minimal increase in heart rate and mean arterial pressure in GATE group which shows that there was adequate analgesia. During sternotomy, additional dose of intravenous fentanyl was given but the haemodynamic response was more in GA group.

We also observed that the stress response to intubation was less in GATE group which is statistically significant. Similar observation was noted by Massimo Caputo et al in $2011^{4}$ Stress response in coronary artery bypass graft surgery can lead to myocardial infarction, arrhythmia and pulmonary oedema. We did not observe any complication after intubation. To have reduction in stress response we need to wait for at least 20 minutes after thoracic epidural dose.

\section{Duration of Surgery}

The median duration of surgery (table 6 ) in GATE group is 5 hours 30 minutes (IQR- $0-1.00$ ) which is significantly higher than GA group with 5 hours (IQR-0-0.63). General anaesthesia was given 20 minutes after epidural infusion so as to have adequate action of epidural anaesthesia which has led to more duration of surgery in GATE group.

\section{Extubation Time}

Patients were extubated in ICU as per institutional protocol. Patients were extubated earlier in the GATE group (Median = 5 hours $+0-7$ ) as compared with GA group (Median=7 hours $+0-5)$ with a significant value at 3-4 hours' period. In GATE group $83.34 \%$ of the patients were extubated earlier within 8 hours as compared to $62.96 \%$ in GA group (Table 7).

The reversible central neuraxial blockade which has sympatholytic effects has the capability to attenuate the response to surgical stress and to improve both myocardial metabolism and perioperative analgesia. These beneficial effects have been proved to enable earlier extubation and a smoother postoperative course. ${ }^{9}$ Superior analgesic and the avoidance of parental opioids and their side effects, led to significant earlier extubation. ${ }^{4}$

Our finding of earlier extubation is similar to the studies conducted by Mark A Chaney et al 2006,11 Massimo Caputo et al $2011^{4}$ and Stefano Casalino et al $2006^{9}$

\section{CONCLUSIONS}

In the present prospective randomised control study, we have observed that combined thoracic epidural anaesthesia with general anaesthesia reduces stress response to intubation, better perioperative haemodynamic stability and earlier extubation. No incidence of epidural haematoma was observed in the study.

\section{REFERENCES}

[1] Prabhakaran D, Jeemon P, Roy A. Cardiovascular diseases in india: current epidemiology and future directions. Circulation 2016;133(16):1605-20.

[2] Mehta Y, Kulkarni V. Thoracic epidural analgesia in cardiac surgery. Ann Card Anaesth 2003;6(2):175-82.

[3] Rajakaruna C, Rogers C, Pike K, et al. Superior haemodynamic stability during off-pump coronary surgery with thoracic epidural anaesthesia: results from a prospective randomized controlled trial. Interact Cardiovasc Thorac Surg 2013;16(5):602-7. 
[4] Caputo M, Alwair H, Rogers CA, et al. Thoracic epidural anesthesia improves early outcomes in patients undergoing off-pump coronary artery bypass surgery: a prospective, randomized, controlled trial. Anesthesiology 2011;114(2):380-90.

http://anesthesiology.pubs.asahq.org/Article.aspx?doi $=10.1097 /$ ALN.0b013e318201f571

[5] Noiseux N, Prieto I, Bracco D, et al. Coronary artery bypass grafting in the awake patient combining high thoracic epidural and femoral nerve block: First series of 15 patients. Br J Anaesth 2008;100(2):184-9.

[6] Murray BW, Trojanowski A. A nonpharmacological three-step test for confirmation of orrect epidural catheter placement. Anesth Analg 1998;87(5):1216-7.

[7] Scott NB, Turfrey DJ, Ray DA, et al. A prospective randomized study of the potential benefits of thoracic epidural anesthesia and analgesia in patients undergoing coronary artery bypass grafting. Anesth Analg 2001;93(3):528-35.

[8] The American Heart Association. Diabetes mellitus: a major risk factor for cardiovascular disease. A joint editorial statement by the American Diabetes
Association; The National Heart, Lung, and Blood Institute; The Juvenile Diabetes Foundation International; The National Institute of Diabetes and Digestive and Kidney Diseases. Circulation 1999;100(10):1132-3.

http://circ.ahajournals.org/cgi/doi/10.1161/01.CIR.1 00.10 .1132

[9] Casalino S, Mangia F, Stelian E, et al. High thoracic epidural anesthesia in cardiac surgery: risk factors for arterial hypotension. Tex Heart Inst J 2006;33(2):14853.

[10] Borde D, Gandhe U, Hargave N, et al. The application of European system for cardiac operative risk evaluation II (EuroSCORE II) and Society of Thoracic Surgeons (STS) risk-score for risk stratification in Indian patients undergoing cardiac surgery. Ann Card Anaesth 2013;16(3):163-6.

http://www.annals.in/text.asp?2013/16/3/163/1142 34

[11] Chaney MA. Intrathecal and epidural anesthesia and analgesia for cardiac surgery. Anesth Analg 2006;102(1):45-64. 